\title{
FUTURE DAIRY FARM EMPLOYMENT - AN APPLICATION OF THE HUMAN CAPABILITY FRAMEWORK
}

\author{
Rupert S. Tipples \\ Jude Wilson \\ Reuben Edkins \\ Xiaomeng Sun
}

Agriculture and Life Sciences Division

Lincoln University

Funded by dairy farmers through Dairy InSight

\begin{abstract}
Dairy InSight research project, no. 10015/2003 sought to establish the future employment needs of the industry from a study of the future dairy farm labour market; to estimate future labour required and available; and to provide a full discussion of factors affecting those estimates. The report on which this paper is based was intended to provide a foundation document for any future studies of work and employment in dairy farming. The research strategy adopted was to use the Human Capability Framework (HCF) to analyse the future dairy farm labour market. The use of the HCF to analyse the future dairy farm employment situation was implemented by a systematic consideration of each of the elements influencing the supply side (Capacity) of the dairy farm labour market, the demand side (Opportunity). and the bringing of those both together (Matching), comprising the three main components of the HCF. Statistical resources were reviewed and found distinctly wanting. Other documentary sources were considered, expert opinions canvassed, and key sites and parties visited, to facilitate the industry wide analysis. All components of the analysis, together with practical recommendations, were put together in a single report, which was submitted to Dairy InSight. the industry good funder for the dairy industry. They are summarised in this paper.
\end{abstract}

\section{Introduction}

The dairy industry is New Zealand's top export earner (\$7.06 billion for year ended 30 June 2002). It generated 23 percent of merchandise exports, and contributed some 7 percent of New Zealand's GDP (MAF, 2004). However, employment in the farm part of this major sector of the economy has been and is problematic (see Edkins and Tipples, 2002, LEW 10). Those problems go back to the first Agricultural Workers Act 1936, when the first Labour Government agreed to support farm incomes through guaranteed prices and rescheduled mortgage payments, if farm workers' incomes were similarly benefited (Tipples, 1987). Their most recent embodiment was the farm labour shortage apparent from the late 1990s (Tipples and Morriss, 2002). On-going concerns about the shortage of dairy farm staff and the changing structure of the industry were significant factors giving rise to this project. It also grew out of a continued frustration with the partial analyses which had taken part previously and the belief that an important source of data had been ignored, which could shed valuable light on this changing sector of employment and the economy.

The report on which this paper is based (Tipples, Wilson and Edkins, 2004) presents the future employment needs of the industry from a study of the future dairy farm labour market. It attempts to estimate future labour required and available, and it provides a full discussion of factors affecting those estimates. The report, funded by Dairy InSight, was intended to provide a foundation document for any future studies of work and employment in dairy farming.

\section{Research strategy}

The research strategy adopted was to use the Human Capability Framework (Tipples, 2004) to analyse the dairy farm labour market. Through this systematic analysis of the supply (capacity) and demand (opportunity) sides of the industry's labour market could be conducted, with all influencing factors being considered in turn. Data sources for this strategy were partial and had to be exploited in an innovative way. No farm labour data had been collected systematically after the demise of the Agricultural Production Census in 1996 (Fairweather, 1997). Dairy production statistics are cow and farm focused. Dairy farm staff have been ignored. Consequently we know more about individual cows than dairy farm staff. However, no systematic analysis of the data collected in the Censuses of Population for dairy farm staff had been made and this seemed to have possibilities.

The project was divided into six parts. First a brief postal survey was conducted of what industry leaders, representatives and professionals thought of the labour and employment troubles being experienced and what should be considered in the study. It contrasted those opinions, which did not show a clear consensus, with the findings of the limited empirical research on the same troubles. The research conclusions were also unable to elucidate the troubles completely as they related to 
different time periods, to different regions and were derived using different research methods.

The opinions gathered from the industry and review of previous empirical research did provide a useful background to the main body of the report. In Part 2 the use of the Human Capability Framework (HCF) was reviewed. The HCF was considered to provide a better picture of the labour market than a simple classical economic model. It achieved this by not just focusing on the demand (opportunity) and supply (capacity) sides of the market, but by also considering factors influencing them and how the matching of demand and supply are actually effected. Previous uses of the HCF were considered such as Tipples' and Morriss' (2002) study of 'the farm labour crisis', Edkins study of dairy farming in the Amuri (2003), and Lucock's study of the role of foreign migrants in resolving the dairy labour crisis in Canterbury (Lucock, 2003). It seemed to be the most relevant model for this particular study, fitted well along side espoused Government policy for the labour market, and provided the chance to consider such diverse factors as the changing influence of demography on the future supply of dairy farm staff and effect of new innovations such as 'Once-a-day' milking (OAD) on the demand for staff, while permitting exploring the relatively new territory of the "matching' of supply and demand for staff. It also provides a focus for proposed interventions.

\section{Capacity - The Future Supply Of Dairy Farm Staff}

The supply side of the dairy farm labour market was considered first. There was an initial review of the current labour force of the industry and how that capacity had evolved as revealed by census data and other descriptive reports. It provided a comprehensive review of what census information did and did not provide.
Dairy farm staff were able to be identified at the 'Occupation' level (Occupation Classification 61211) which covered all dairy farmers and dairy farm workers. This included cadets, farm hands, managers, supervisors, workers, farmers, stud farmers, milking equipment operators and sharemilkers. While the classification did not differentiate between employers and employees it did include all those engaged in dairying on-farm. It is this population that is discussed throughout as 'dairy farmers/dairy farm workers'. StatisticsNZ advised that the information available from the 1991, 1996 and 2001 Censuses of Population and Dwellings were comparable, but only sometimes with the redefinition of changed statistical areas. They were analysed by occupational status, ethnicity, age, sex, qualifications, hours worked and region.

\section{Occupation Versus Industry}

The census records labour force statistics in several quite different forms. At the 2001 census there were 26331 people employed by 'occupation' as dairy farmers/dairy farm workers in New Zealand. This is a lower count than is often reported for the dairy industry workforce as it records only 'on farm' dairy workers who recorded dairy farming as their occupation in their main job. By way of contrast there were 35037 people employed in the dairy 'industry' at the same census. For the resident population on census night 'occupation' in main job is recorded, as is who employs them. From these sets of figures a calculation is made of the numbers employed in any given industry. Thus it is possible to be employed in occupations other than 'dairy farmers/dairy farm worker' and yet be counted in the dairy farming industry figures. Unless otherwise stated all figures referred to in this paper refer to the occupation count.

Figure 1: The Dairy Farm Labour Market as an HCF Diagram

Key Capacity, Matching, and Opportunity Trends for the Dairy Farm Labour Market (Workforce 2010) - highlighting interactions within the Human Capability Framework

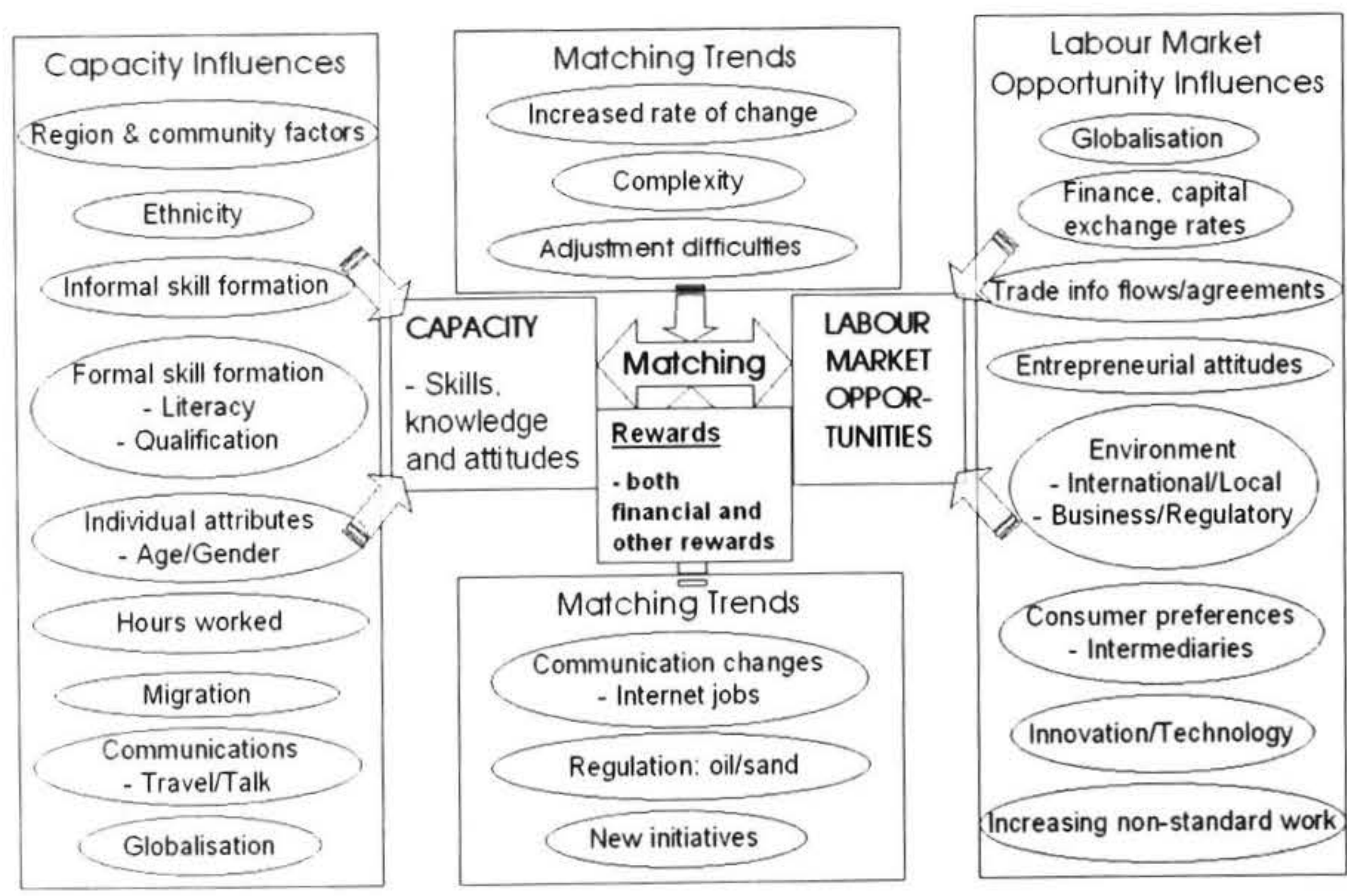




\section{Regional distribution}

Figure 2 shows the regional distribution of dairy farms and farmers and farm workers. Levels of employment are highest in Waikato/Bay of Plenty and Canterbury.

\section{Figure 2: Regional Distribution of DF Workers and Dairy Farms}

(Source: Statistics NZ \& Dairy Statistics 2001-2002)

Regional Distribution of DF Labour and Dairy Farms

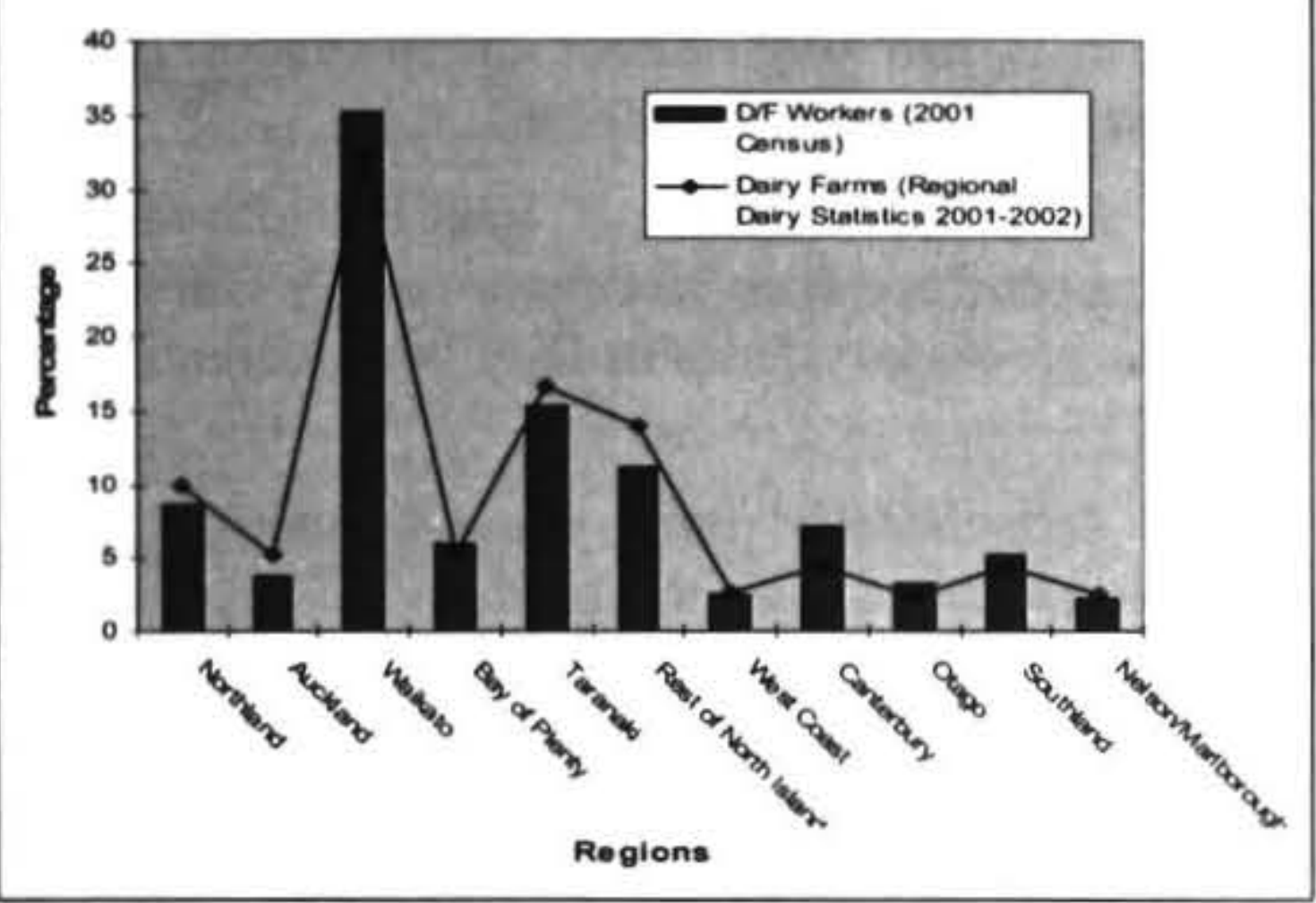

\section{Status in Employment}

Status in Employment classified people according to whether they were working for themselves or for other people. By this classification the working population was separated into 'paid employees', 'employers', 'self employed without employees' and 'unpaid family workers'.

The main operating structures found on New Zealand dairy farms are owner operator, sharemilker and contract milker (Dairy Statistics, 2002-2003). This accounted for the high percentages of the dairy farmers/dairy farm workers population in the 'self-employed and without employees' category, as many farms only employed additional labour on a casual or seasonal basis. Traditionally the dairy industry has had a high proportion of unpaid family workers. Figure 3 suggests that this operating structure may be changing. The proportion of 'employees' and 'employers' have increased over time while the number of 'self employed without employees' has fallen. The gender balance has remained similar, although traditionally a higher proportion of those recorded as 'unpaid family workers' are female.

\section{Figure 3: Status in Employment over Time} (Source: Statistics NZ 1991, 1996 \& 2001 Census)

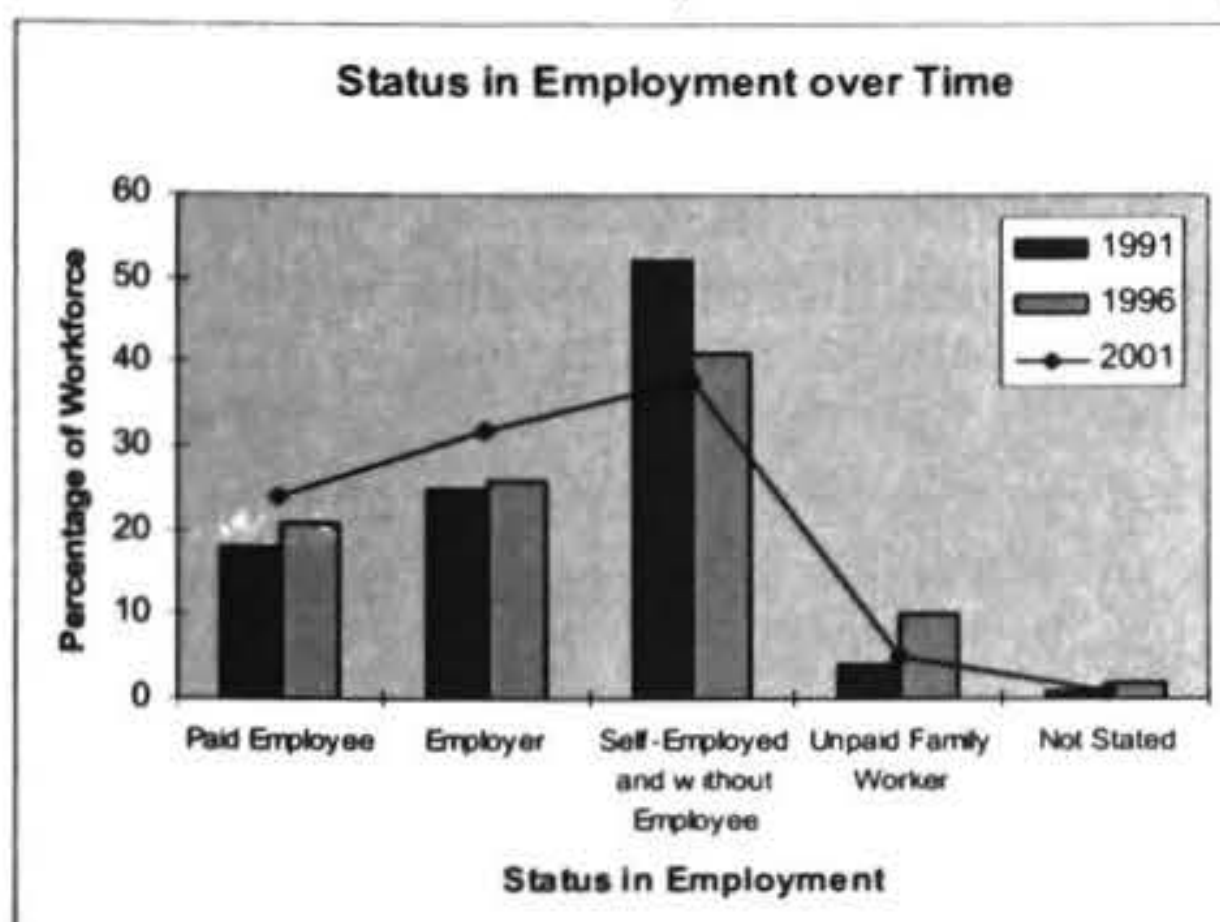

Age

The age structure of the dairy farmers/dairy farm workers population in 2001 was similar to that of the working population as a whole. While the industry appears to attract young entry level workers, this was not maintained in the same proportions as in the working population as a whole, especially the age groups immediately following the 15-19 year age group. There is potential for this shortfall to increase as a problem for industries such as dairying because the New Zealand population is predicted to alter significantly in age structure over the coming decades. The numbers available in the youth segment of the labour force are declining and will continue to do so. The 18-24 year segment of the labour force is expected to make up only 12 percent of the labour force in 2051 , compared with 16 percent in 1996. Those aged 45-64 are expected to increase their share of the labour force from 28 percent in 1996 to 40 percent in 2051 (New Zealand Labour Force Projections). Some evidence of population ageing can be seen in the changing age structure of the dairy farmers/dairy farm workers population over the last three censuses (see Figure 4). Ageing of the dairy farmer/worker population is particularly acute in Northland.

\section{Figure 4: Age Distribution across Census Years} (Source: Statistics NZ 1991, 1996, 2001 Census

Age Distribution Dairy farmers/Dairy farm workers

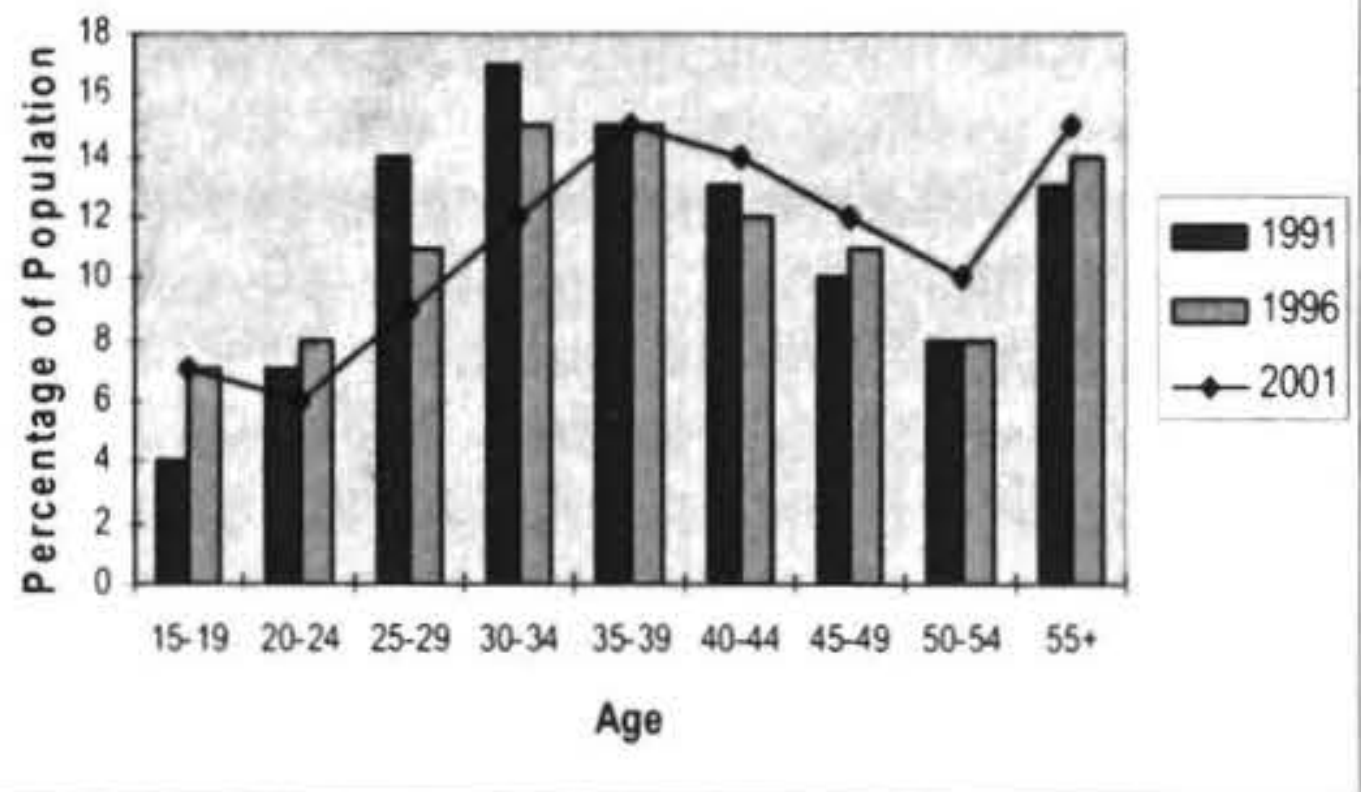

\section{Ethnicity}

At the 2001 census of the total 26,331 persons employed as dairy farmers/dairy farm workers 1300 ( 5 percent) were Maori. One in seven (14.3 percent) of the New Zealand population as a whole identified as Maori. The Maori ethnic group has a younger age structure and higher birth-rate than the non-Maori population and thus has potential to increase its portion of the New Zealand population. This may also increase the percentage of Maori involved in dairying, although as Table 1 shows, a considerably larger number $(14,850)$ of Maori were employed in agricultural occupations other than dairying at the 2001 Census.

Table 1 shows the numbers employed, by ethnicity, for all agricultural occupations at the 2001 census. Agricultural employment is predominantly undertaken by those of European ethnicity. In the total population there has been a fall in the number of people recording European ethnicity from 83 percent in 1991 to 80 percent 
in 2001. Counts of people of Asian ethnicity have more than doubled between 1991 and 2001. The column to the right in Table 1 shows the percentage increase for each of the main ethnic groups between 1991 and 2001. Those with the smallest representation in the agricultural workforce are the fastest growing segments of the New Zealand population. Immigration has the potential to further change the ethnic balance in New Zealand.

\section{Table 1: Agriculture occupation and Population increase by Ethnicity}

(Source: Statistics NZ 2001 Census)

\begin{tabular}{|l|l|l|}
\hline Ethnicity & $\begin{array}{l}\text { Occupation } \\
\text { Agriculture }\end{array}$ & $\begin{array}{l}\text { \%opulation } \\
\text { Poprease } \\
\text { Inc1-2001 }\end{array}$ \\
\hline Total European & 122610 & 3.0 \\
\hline Total Maori & 14850 & 21.0 \\
\hline Total Pacific & 2208 & 38.7 \\
\hline Total Asian & 2736 & 138.0 \\
\hline Total Other & 168 & $\mathrm{n} / \mathrm{a}$ \\
\hline
\end{tabular}

\section{Hours worked}

The largest difference between the dairy farm population and the general working population was the much greater proportion ( 64 percent) working more than 50 hours per week: (agricultural population 40 percent, general working population 25 percent). The hours worked have also changed over time within the dairy farmers/dairy farm workers population as Figure 5 shows. This shows a percentage decrease in the numbers of part time workers and increases in those working 70+ hours per week. Otherwise there had been little change since 1996.

Figure 5: Hours Worked by Census Year by Dairy farmers/dairy farm workers Population

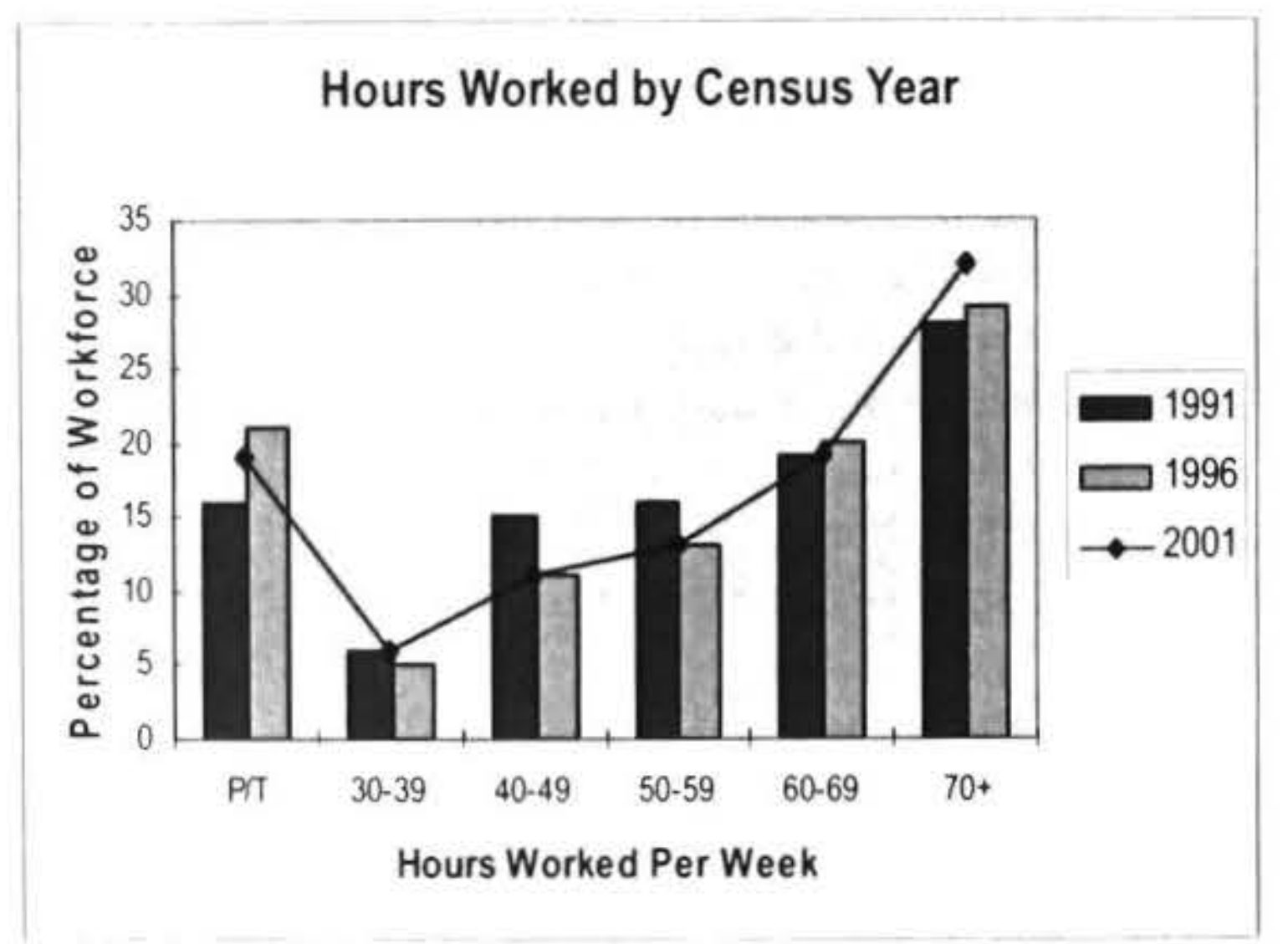

(Source Statistics NZ 1991, 1996 \& 2001 Census)

\section{Qualifications}

The highest qualifications held by the 2001 dairy farmers/dairy farm workers population is shown in Table 2. Some comparison can be made with the highest qualifications attained by the New Zealand working population. This shows that overall in the working population:

$>\quad 1$ in 4 had no qualifications (dairy farmers/dairy farm workers 1 in 3.5)

$>1$ in 3 had post school qualifications (dairy farmers/dairy farm workers 1 in 4)

$>1$ in 5 had vocational qualifications (dairy farmers/dairy farm workers 1 in 4.7) 1 in 8 had a degree (dairy farmers/dairy farm workers 1 in 25)

The dairy farmers/dairy farm workers population is poorly educated in comparison to the total population, especially the number who have degree qualifications. As might be expected, however, the dairy farmers/dairy farm workers population is slightly better represented with vocational qualifications. There are several points worth noting from more detailed analysis of these statistics, especially in response to calls from within the dairy industry for more skill training and tertiary education of the workforce.

Table 2: Highest Qualification 2001 Dairy Population (Source: Statistics NZ 2001 Census)

\begin{tabular}{|l|c|c|}
\hline Highest Qualification & Number & Percentage \\
\hline No Qualification & 7602 & 29 \\
\hline School Qualification & 10497 & 40 \\
\hline $\begin{array}{l}\text { Vocational } \\
\text { Qualification }\end{array}$ & 5448 & 21 \\
\hline Degree & 1035 & 4 \\
\hline Unidentified/Not stated & 1749 & 6 \\
\hline Total & $\mathbf{2 6 3 3 1}$ & $\mathbf{1 0 0}$ \\
\hline
\end{tabular}

Altogether over 50 percent of females with vocational qualifications held them at advanced level. In contrast only 25 percent of males had advanced level vocational qualifications. For males with vocational qualifications 'skilled' was the most common level achieved e.g. Apprenticeships and National Certificate at Level 4. There was some gender imbalance in highest qualifications attained with a larger percentage of females holding both school and degree qualifications. A slighter larger percentage of males ( 21 percent) held vocational qualifications than did females ( 20 percent). Differentiation of vocational qualifications by skill level and sex are shown in Table 3 . Those aged $50+$ accounted for 40 percent of those with no qualifications at all. Of the 16590 dairy farmers/dairy farm workers with no post-school qualifications the age spread was more even, although 27 percent of this group were also over the age of 50 . 
Table 3: Vocational Qualification By Sex - (Source: Statistics NZ 2001 Census)

\begin{tabular}{|l|r|r|r|r|r|r|}
\hline Vocational Qualification & Male & $\%$ & Female & $\%$ & Total & $\%$ \\
\hline Basic & 750 & 20.6 & 360 & 19.9 & 1110 & 20.4 \\
\hline Skilled & 1509 & 41.5 & 393 & 21.8 & 1902 & 34.9 \\
\hline Intermediate & 447 & 12.3 & 147 & 8.1 & 594 & 10.9 \\
\hline Advanced & 930 & 25.6 & 909 & 50.2 & 1839 & 33.8 \\
\hline Total & $\mathbf{3 6 3 6}$ & $\mathbf{1 0 0}$ & $\mathbf{1 8 0 9}$ & $\mathbf{1 0 0}$ & $\mathbf{5 4 4 5}$ & $\mathbf{1 0 0}$ \\
\hline
\end{tabular}

\section{Regional variation}

Dairy farming had different characteristics regionally. Waikato/Bay of Plenty and Canterbury are contrasted as an example. The scenario of each region was based on the census data available and the snapshot provided by the MAF Dairy Monitoring Report for 2003.

\section{Waikato/Bay of Plenty}

Typically a dairy farm has an owner-operator who milks the cows and employs a permanent (single) worker. Some farm owners with larger herds who employ a number of staff have increased the time off for leave and training to try and attract good quality staff, and there is a major educational push into upskilling those involved in the industry, both farmers and workers. There continues to be a strong demand for $50 / 50$ sharemilking positions as available, but some larger farms have moved from employing a 50/50 sharemilker to employing a variable order sharemilker or a manager on wages.

\section{(Source: MAF Dairy Monitoring Report,} July 2003: 12-18)

There were 10,824 dairy farmers/dairy farm workers at the 2001 census, 41 percent of the New Zealand total.

Both Waikato (16 percent) and the Bay of Plenty (18 percent) had higher percentages in the 55+ age groups than the national dairy farmers/dairy farm workers population ( 15 percent). These regions were both poorly represented by those in the 20-24 and 2529 age groups.

They had the highest percentage with vocational qualifications ( 23 percent) and the lowest percentage with school qualifications (39 percent).

Similar to Northland, a high percentage of dairy farmers/dairy farm workers in these regions were 'self employed without employees' (42 percent compared with the national figure of 38 percent).

\section{Canterbury}

There are very few large sharemilking positions in Canterbury. Corporate owners and owners of large farms are choosing to employ managers or equity managers. There is a dependence on overseas workers. One of the reasons that motivated young people to stay in the industry is so that they can work toward a large sharemilking position and then buy their own farm. This pathway seems to be under serious pressure. If it were not for overseas workers the industry would already be seriously under-staffed.

(Source: MAF Dairy Monitoring Report, July 2003: 28-35)

There were 1,857 dairy farmers/dairy farm workers in Canterbury, 7 percent of the New Zealand total at the 2001 Census. Canterbury was particularly well represented in the younger age groups. Over 15 percent of its dairy farmers/dairy farm workers population was in the 15-19 year age group. This compared with a national dairy farmers/dairy farm workers figure of only 7 percent. Those in the 20-24 and 25-29 year groups were also better represented.

$>\quad$ Canterbury had the lowest percentage with no qualifications $(25.1$ percent $)$ and the highest percentage with both school (42.9 percent) and degree $(5.5$ percent $)$ qualifications. These compare with national percentages of 28.9 percent with no qualifications, 39.9 with school qualifications and 3.9 percent with degrees.

In Status in Employment Canterbury differed markedly from the national dairy farmers/dairy farm workers population. Only 12 percent of those in Canterbury were 'self employed without employees' (nationally 38 percent). Forty-six percent were paid employees, compared to only 24 percent nationally.

\section{Dairy farm migrations}

The pattern of employment in the dairy farming industry is unique. The analysis of census data was extended when it was discovered that the data could reveal the whereabouts of the individual dairy person five years 
previously. This enabled analysis of the overall patterns of migration undergone by dairy farm staff. Historically dairy farmers, sharemilkers and their employees have changed farms on 'Gypsy day', 1 June (Tipples and Lucock, 2004). The successive censuses (1991, 1996 and 2001) showed the overall patterns of inter-censal migration. Thus we were able to derive the first empirical account of the migrations which the dairy farm labour force has experienced between 1986 and 2001.
For North Island districts some 15 percent of total dairy farmers/dairy farm workers per region had moved regions between censuses. For South Island districts the proportion, which had moved, was nearer 25 percent, but that related to much smaller numbers involved. Overall, there had been a marked move to the South Island between 1991 and 1996, which had slowed between 1996 and 2001. At the same time the amount of movement within the South Island had continued to grow.

Figure 6: Migration Synopsis

(Source: Statistics NZ 1991, 1996 and 2001 Census)

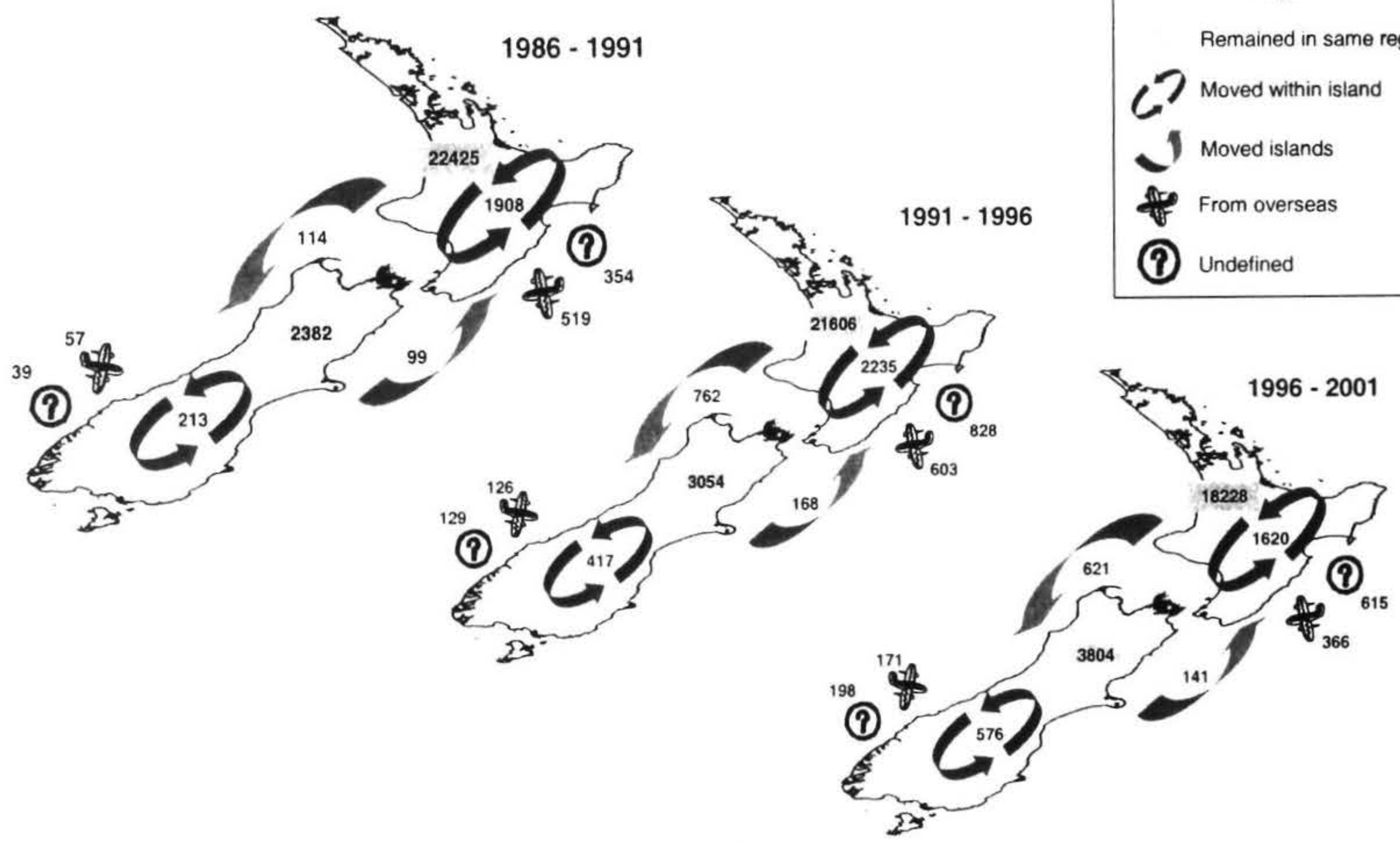




\section{Opportunity - the future demand for dairy farm staff}

\section{Structural factors}

The demand side of the dairy farm labour market, the opportunities available for the dairy farm workforce, was first considered from a structural point of view. First, the decreasing number of dairy farms was contrasted with the considerable increase in the number of cows over the twenty years to $2002 / 2003$. Thus the numbers of small herds has declined and large herds increased, while the area of farms has increased at a slower rate because of more intensive stocking. Consequently, there are larger and more complex farms and herds, which require greater management skill by employers and increasing numbers of employees, who also have to be 'managed'. Regional differences were again significant.

\section{Entrepreneurial attitudes}

Entrepreneurial attitudes, particularly of small business enterprise owners, which would include most dairy farmers, were considered and found to have similar effects - difficulties of delegation, working very long hours (a major problem for many prospective dairy farm staff), stressful lifestyles, and dependence on employees. Statutory compliance was always an issue, particularly with what was seen as the increasing tide of regulation of employment and safety conditions. The prospect of future farm ownership seems more remote and less of an incentive to work up from the lower rungs of the traditional dairy farming career ladder than it had done.

\section{Environmental factors}

Other drivers of demand were also reviewed, including the international and New Zealand business and regulatory environments. International changing consumer preferences, highlighted by the growing demand for quality assurance programmes, will have an influence on workforce demand, as will the desire to maintain New Zealand's 'clean, green image'.

\section{Consumer preferences}

The need for product traceability for food safety and health reasons, from producer to consumer, and for publicly accepted animal welfare and employee welfare standards, increasingly required by supermarkets (e.g. Eurepgap protocols), will require the ability to document and trace back production. A need for greater literacy and computing skills will be the consequence.

\section{Innovation}

Changing production systems also have quality assurance implications. The widespread adoption of 'Once-a-day' milking could have a major impact on QA programmes because it is relatively 'cow friendly', which would suit a QA programme with animal welfare concerns such as Eurepgap, while at the same time it has a major implication of a reduced demand for labour. Since we completed our study there has been a huge growth in industry interest in this system. With intensive breeding to harness the benefits of the OAD system, this could be one of the biggest changes the industry has seen since the abandoning of stripping cows before milking, with substantial effects on those working with such systems.

\section{Technological change}

The major technological change nearing maturity is the Automated Milking System. This fully robotic milking system, such as on Dexcel's fully automated Greenfield site at Ruakura, can be operated by the farm worker from off site by means of just a cell phone alarm, which alerts him if there is a system malfunction.

If these two changes can be successfully integrated together the staffing implications might include a smaller but more technically competent and qualified work force.

\section{Non-standard work}

The tightness of the dairy farm labour market has forced the adoption of a number of employment practices which have been more employee friendly to ensure a continued supply of staff. These changes have often involved some element of working outside normal hours or shifts, and a degree of casualization. They reflect trends in society at large.

\section{Matching}

Matching processes bring together supply or capacity with demand or opportunity. The consideration of matching processes in themselves is a relatively new field and one in which the industry can make radical improvements. They were not found not to be working very well in our study.

An example of poor matching comes from a Taranaki study, part of dairy heartland, where you would not expect it to be a problem. There was misinformation there and school students often had poor perceptions of dairy farming and believed their chances of employment in the dairy sector were poor. Also they did not want to work weekends and believed social life in the dairy sector was poor. Further they believed higher levels of education were not necessary for dairy farming.

Careers counsellors' attitudes to agriculture and dairying were also of concern, but farmers' negative attitudes about the prospects of their own industry were not believed to help either. Poor matching of job applicants with job expectations was an ongoing problem, with poor stereotypical images of the industry. The evidence for the existence of long hours, one of the contentious issues of most concern to both industry recruits and those already employed was incontrovertible. 
New forms of matching (e.g. internet job advertising) might appear to be helping, but they depend on ready access to and the ability to use a computer. Further, they rarely provide full information for a job applicant, an important part of founding good employment relationships.

Regulation of employment conditions can be regarded as both oil to help the relationships run more smoothly and the sand which creates an element of friction. Failure of statutory compliance can cause difficulties in achieving good matches.

Work to improve matching at overall industry level has been the focus of the pan-industry group, Human Capability in Agriculture and Horticulture since 2002, which includes a promotional strategy, careers and schools programmes, together with meeting careers' advisors (Tipples, 2004).

Dexcel, with its People4dairying programme and 'toolkit', and Dairy InSight, are already engaged in various programmes to help matching e.g. 'Let's Talk Dairying'. Farmer initiatives have also had some spectacular successes such as the Amuri Dairy Employers Group around Culverden in Canterbury (Edkins, Reuben, 2003).

The growth in matching 'initiatives' since 2000 may be seen very positively, but the industry is warned against losing its current positive momentum. Short term cost cutting in the event of adverse terms of trade, as has happened in the past could rapidly undo the good work of the last few years. With an increasing dependence on employed staff potential recruits could be driven away.

\section{Estimating future dairy farm staff}

The problems of forecasting or estimating the scale of future staffing needs were found to be considerable. The hazards in such a process were illuminated by a case study of Canterbury, when in 1993 estimates were required of numbers of horticultural staff in the $21^{\text {st }}$ Century. At that time data sources of both staff and production areas were much better than now. Even so three out of four estimates were wildly wrong compared to the number of persons recorded in the 2001 Census of Population, the worst by a factor of 5.5. Since 1996 the basic data to support such estimations is no longer collected. Census of Population data for 1991, 1996 and 2001 were insufficiently compatible to permit better estimations. In this situation, where precise estimation was very difficult, it is important to understand how and why the critical variables are changing. Consequently, a particular estimation of the future staffing level for dairy farming in 2030 was suggested as reasonable. All the factors affecting the component parts were discussed, so that if any one cause of change was not what was expected a reasonable re-evaluation of the estimate might be made

\section{For 2030, Holmes and Cameron have suggested:}

"4 million cows; 9,000 herds; average 440 cows per herd, average 3 staff per farm, on the 8,000 largest farms, with at least one person with tertiary (or equivalent) training, and the other two staff either having already completed, or currently working through, the industry's apprenticeship programme." (Holmes and Cameron, 2001, 54)

If we assume that the 1,000 smallest farms will not employ significant numbers of staff except the immediate farm family, which will be counted as 1.5 staff equivalents, the workforce would be some $24,000+$ $1,500=25,500$ staff equivalents. That total includes both farmer/operators plus employees, whether full or part-time, whether male or female. That is only slightly less than the number identifying themselves as full-time dairy farmers/farm workers at the 2001 census. If the industry continues to expand and businesses continue to get bigger in size, then a further growth in employment is anticipated as family involvement diminishes. Where a greater proportion of employees are to come from, with New Zealand's fast aging and ethnically diverse population, is a moot point.

\section{Conclusions and Recommendations}

1. The capacity/supply of labour within and available to the dairy industry is unlikely to meet the future opportunities/demand.

2. Future capacity is compromised by a small and probably declining number of entrants from a more urban and ethnically diverse pool of potential staff; inadequate numbers training and achieving technical competence; and by poor retention.

3. Growth in opportunities is expected to continue with increasing total cow numbers and increasing farm scale, especially in areas which are remote or sparsely populated, often with little dairying history.

4. Literacy and technical requirements of employers and employees will continue to increase.

5. The increase in the amount and level of debate about the industry's employment troubles is a very encouraging development. Greater awareness of and willingness to do something about the industry's employment troubles indicates a groundswell necessary for improvement. The change needs to be encouraged in every way possible.

6. The data available for estimation of future availability and need for staff are totally inadequate. The dairy farming industry needs to have good workforce data collected on a regular and systematic basis.

7. If Once-a-Day milking (OAD) is widely adopted, and cows selected for best OAD characteristics, the implications for the demand for labour could be considerable. Workshops held during 2004, since our report was 
submitted, have had unprecedented interest from dairy farmers. OAD might have vast advantages for recruiting and retaining staff because it is much more 'worker friendly' and offers real lifestyle advantages. Dairy farmers and workers might indeed 'get-a-life'!

8. To keep improving labour productivity in the sector the need for further mechanization of labour intensive processes is ongoing. The continued pursuit of the Automatic Dairy Farm is critical and the funding that implies needs to be continued.

9. In terms of the future to 2030 , Holmes and Cameron's 2001 estimations of prospective supply and demand for staff are re-affirmed. The assumptions on which they are based seem perfectly reasonable in the light of the matters discussed in this report. To force the data to say more would be unreasonable and unethical. Whether what those estimations imply can be achieved is debatable.

10. A shorter term strategy for more immediate labour requirements is suggested, using temporary migrants. Some dairy farming job categories are already listed among occupational shortages.

\section{Future research}

Further research on the changing barriers to entry into a dairy career or job is going to continue to be worth study. Continued retention difficulties similarly merit further consideration, especially tactics for employers to adopt to reduce the problem. The implications of Oncea-day milking are most exciting and their employment implications need careful study. Finally more work on Automatic Milking Systems seems to present some of the greatest opportunities for improved labour productivity to help the industry meet its 4 percent annual goal for productivity increases.

\section{References}

Edkins, Reuben (2003) Dairying and Employment in the Amuri district, north Canterbury: 1983-2002. M. $\operatorname{Com}(\mathrm{Ag})$ thesis, Lincoln University, Canterbury.

Edkins, Reuben and Tipples, Rupert (2002) Dairying and employment in the Amuri 1983-2002. In Blumenfeld, Stephen B. (ed.) Labour, Employment and work in New Zealand Proceedings of the Tenth Conference, 21 and 22 November, Victoria University of Wellington.
Fairweather, John R. (1997) Implications and Impacts of Land Use Change: Adventures with Agricultural Statistics. New Zealand Agricultural and Resource economics Society Conference, Blenheim, 4 July. AERU, Lincoln University, Canterbury.

Lucock, David (2003) The integration of immigrants into the New Zealand Dairy Farm System. Dissertation submitted as part of a B. Agr. Sc. (Hons) degree, Lincoln University.

Ministry of Agriculture and Forestry (2004) Situation and Update for New Zealand Agriculture and Forestry. http://www.maf.govt.nz/mafnet/rural$\mathrm{nz} /$ statistics-and-forecasts/sonzaf/2004/04update/httoc.htm. 10/09/2004.

Ministry of Agriculture and Forestry (2003) Dairy Monitoring Report. Wellington.

Tipples, Rupert (1987) Labour Relations in New Zealand Agriculture. Sociologia Ruralis, XXVII, $1,38-54$

Tipples, Rupert (2004a) The Human Capability Framework - An Important and useful Framework for Understanding the Labour Market. New Zealand Journal of Employment Relations, 29, 1, 3-20.

Tipples, Rupert (2004b) A Solution to 'Too few' Working Down on the Farm - the Human Capability in Agriculture and Horticulture Initiative. Paper presented at the Eleventh Labour, Employment and Work Conference, Victoria University of Wellington, November 2223.

Tipples, Rupert and Morriss, Stuart (2002) The Farm Labour Crisis. Primary Industry Management, 5 , $3,25-27$.

Tipples, Rupert, Wilson, Jude and Edkins, Reuben (2004) Future Dairy Farm Employment. Dairy InSight Research Contract 10015//2003. 116pp.

Tipples, Rupert and Lucock, David (2004) Migrations and dairy farming. Primary Industry Management, 7, 1, 33-35. 